\title{
Pelvic Incidence as a Determinant for Chronic Low Back Pain: Few Comments
}

\author{
Mohamed Amin Ghobadifar \\ Zoonoses Research Center, Medicine School, Jahrom University of Medical Sciences, Jahrom, Iran
}

Dear Editor,

Ashraf and his colleagues should be praised for bringing much needed attention to the debate about the relationship between the functional status of patients with chronic lower back pain, and lumbar lordosis [1]. Although their study did not result any significant correlation between the score of functional disability and lumbar lordosis, it did point out the potential role of pelvic incidence (PI) as a predictive factor for chronic lower back pain.

Chronic lower back pain is related to the degeneration of the lumbar back muscle, mostly in middle-aged women, andis considered to be one of the most common spinal deformities in many Asian countries [2]. Research has also showm that Spinopelvic parameters are also possible factors related to the degeneration of back muscles. Thus, many studies about the degeneration of the lumbar back muscle are key in order to find clinically significant results.

The key of spinopelvic parameters for sagittal balance is PI, a constant anatomical value, independent of pelvic positioning. PI increases while lumbar lordosis is developing, but it does not change after adolescence. PI defines the extent of pelvic tilt (PT) and sacral slope (SS) $(\mathrm{PI}=\mathrm{PT}+\mathrm{SS})$, and $\mathrm{PT}$ and SS vary based on pelvic positioning. Abnormal spinopelvic parameters and high
PI also attribute to multiple spine conditions, including junctional kyphosis, spondylolysis, adjacent segment degeneration, and degenerative spondylolisthesis $[3,4]$. In the study of Lee et al. [5] PI played an important role for the surgical outcome of degenerative flat back. In another study by Gottfried et al. [6], patients with fixed sagittal imbalance had a large lumbar lordosis and an elevated PI as the pelvic retroversion progressed after spinal fusion surgery. In addition, a recent retrospective case series study showed the increasing tendency of PI during the progression of back muscle degeneration [7].

As discussed from above, PI plays a potential role as a predictive factor for chronic lower back pain. In this regard, individual patient data meta-analysis and randomized trials should focus more on this area to help find a way to decrease chronic lower back pain.

\section{Conflict of Interest}

No potential conflict of interest relevant to this article was reported.

\section{References}

1. Ashraf A, Farahangiz S, Pakniat Jahromi B, Setayeshpour N, Naseri M, Nasseri A. Correlation between

Received Dec 14, 2014; Revised Dec 14, 2014; Accepted Dec 15, 2014

Corresponding author: Mohamed Amin Ghobadifar

Zoonoses Research Center, Medicine School, Jahrom University of Medical Sciences,

Motahari Avenue, Jahrom, Iran. Postal Code: 193

Tel: +98-936-620-8078, Fax: +98-711-636-13-86, E-mail: amin_m505@yahoo.com 
radiologic sign of lumbar lordosis and functional status in patients with chronic mechanical low back pain. Asian Spine J 2014;8:565-70.

2. Jimbo S, Kobayashi T, Aono K, Atsuta Y, Matsuno T. Epidemiology of degenerative lumbar scoliosis: a community-based cohort study. Spine (Phila Pa 1976) 2012;37:1763-70.

3. Vialle R, Ilharreborde B, Dauzac C, Lenoir T, Rillardon L, Guigui P. Is there a sagittal imbalance of the spine in isthmic spondylolisthesis? A correlation study. Eur Spine J 2007;16:1641-9.

4. Labelle H, Roussouly P, Berthonnaud E, et al. Spondylolisthesis, pelvic incidence, and spinopelvic balance: a correlation study. Spine (Phila Pa 1976) 2004;29:2049-54.

5. Lee CS, Lee CK, Kim YT, Hong YM, Yoo JH. Dynamic sagittal imbalance of the spine in degenerative flat back: significance of pelvic tilt in surgical treatment. Spine (Phila Pa 1976) 2001;26:2029-35.

6. Gottfried ON, Daubs MD, Patel AA, Dailey AT, Brodke DS. Spinopelvic parameters in postfusion flatback deformity patients. Spine J 2009;9:639-47.

7. Nam WD, Chang BS, Lee CK, Cho JH. Clinical and radiological predictive factors to be related with the degree of lumbar back muscle degeneration: difference by gender. Clin Orthop Surg 2014;6:318-23. 